\title{
Muscle free amino acid profiles are related to differences in skeletal muscle growth between single and twin ovine fetuses near term
}

\author{
Francisco Sales ${ }^{1,2,4}$, David Pacheco ${ }^{1}$, Hugh Blair ${ }^{2,3}$, Paul Kenyon $^{2,3}$ and Sue McCoard ${ }^{1,2^{*}}$
}

\begin{abstract}
Twin sheep fetuses have reduced skeletal muscle weight near birth relative to singles as a result of restricted muscle hypertrophy. Intracellular free amino acids (FAA) are reported to regulate metabolic pathways which control muscle protein accretion, whereby reduced intracellular content of specific FAA may reduce their activation and therefore, muscle hypertrophy. The aim of this study was to determine whether differences in muscle weight between singleton and twin fetuses, under different maternal conditions is associated with reduced concentration of specific FAA. The FAA content in the semitendinosus muscle (ST) in singleton and twin fetuses (rank) at 140 days of gestation from heavy $(H)$ or light $(L)$ ewes fed ad libitum $(A)$ or maintenance $(M)$ level of nutrition was measured. Muscle weight was reduced in twin fetuses compared to singletons in all groups. Reduced concentrations of leucine, threonine and valine, but higher concentrations of methionine, ornithine, lysine and serine were found in twin fetuses compared to singletons. Maternal size and nutrition interaction with rank resulted in reduced glutamine in twins from HM-ewes (H-ewes under M nutrition) compared to their singleton counterparts. Maternal weight interaction with pregnancy rank reduced the concentration of arginine in twins, with a larger effect on $\mathrm{H}$-ewes compared with L-ewes. Maternal size interaction with pregnancy rank resulted in twins from M-ewes to have lower alanine, while twins from A-ewes had lower aspartic acid concentration compared to singletons. The ST muscle weight was positively correlated only with arginine concentration after taking into account rank, size and nutrition. The present results indicate that reduced concentrations of specific intracellular FAA, such as arginine, leucine, valine, glutamine, which are known to play a role in muscle growth, could be acting as limiting factors for muscle hypertrophy in twin fetuses during late gestation. Ewe size and nutrition can influence the concentration of specific FAA in muscle and should be considered in any intervention plan to improve twin fetal muscle growth.
\end{abstract}

Keywords: Free amino acid; Fetal muscle; Gestation; Muscle growth; Sheep

\section{Background}

Increasing prolificacy is an effective way to improve profitability in sheep production systems (Gootwine et al. 2001). However, birth weight, postnatal survival, growth, body composition and lifetime production performance may be reduced as litter size increases (Barker 1998; Greenwood et al. 1998; Morel et al. 2009). Reduced fetal weight near term in twins compared to singletons is associated with decreased skeletal muscle

\footnotetext{
* Correspondence: sue.mccoard@agresearch.co.nz

'Animal Nutrition Team, Animal Nutrition and Health Group, AgResearch, Grasslands Research Centre, Palmerston North, New Zealand

${ }^{2}$ Gravida: National Research Centre for Growth and Development, Auckland, New Zealand

Full list of author information is available at the end of the article
}

hypertrophy, leading to reduced muscle mass (McCoard et al. 2001). Although maternal undernutrition has a direct effect on fetal and skeletal muscle growth during gestation (Fahey et al. 2005), reduced fetal weight and muscle weight in twins compared to singles is observed even in well-nourished ewes (Freetly and Leymaster 2004). This suggests maternal nutrition is not the only factor to impact fetal and muscle growth as litter size increases.

It is well established that fetal growth is influenced by fetal amino acid (AA) availability (De Boo et al. 2005; Kwon et al. 2004; Liechty et al. 1999). Studies in sheep indicate that the rate of protein accretion in the fetus can be stimulated through the fetal infusion of a mix of 
AA (De Boo et al. 2005; Liechty et al. 1999). Importantly, AA also have the capacity to signal to metabolic pathways which regulate muscle growth (Brown et al. 2009; Hara et al. 1998) via changes in the intracellular concentration of specific AA (Beugnet et al. 2003; Christie et al. 2002; Sancak et al. 2008). For example, AA signalling plays an important role in the regulation of skeletal muscle hypertrophy in monogastrics, through the activation of specific cell signalling pathways (e.g. mechanistic target of rapamycin, mTOR), which controls protein synthesis (Tan et al. 2009; Yao et al. 2008). However, the potential for specific AA to act as signalling molecules to regulate skeletal muscle hypertrophy during gestation in ruminants is not well understood.

In sheep, we have preliminary evidence (Pacheco et al. 2010) that concentrations of specific intracellular AA in skeletal muscle (e.g. arginine and glutamine), differ between single and twin fetuses in late gestation in nutritionally-restricted ewes. The purpose of this study was to further explore the potential relationship between skeletal muscle mass and intracellular free AA concentration in twins compared to singletons, by testing two hypotheses. Our first hypothesis is that reduced skeletal muscle weight in twin, compared to single fetuses in late gestation, is associated with reduced concentration of specific free AA in muscle, such as glutamine and arginine. Our second hypothesis is, that dam nutrition and body size influence the relationship between skeletal muscle AA and fetal muscle weight, between pregnancy ranks (single vs. twin). To test these hypotheses, the concentration of free AA from the semitendinosus (ST) muscle collected from twin and singleton fetuses at 140 days of gestation from heavy and light ewes fed two differing planes of nutrition were compared.

\section{Results}

A three-way interaction between pregnancy rank, size and nutrition was observed for ST weight $(P=0.04$, Figure 1). Twins from HM-ewes had lower ST weights compared with twins from HA-ewes, whereas singletons from LM-ewes had lower ST weight compared with LA singletons (Figure 1). After adjusting for fetal body weight, only a pregnancy rank effect was observed, whereby twins had $17 \%$ lower ST weight compared to singles $(8.3 \pm 0.3 \mathrm{~g}$ vs. $10.0 \pm 0.3 \mathrm{~g}, P=0.002)$. No maternal size, maternal nutrition or interactions with maternal size or nutrition effects were observed for ST weight (data not shown).

A three-way interaction between pregnancy rank, maternal size and plane of nutrition was observed for ST intracellular concentrations of free glutamine and tyrosine (Table 1). Twin fetuses from HM-ewes had 37\% lower $(P=0.0003)$ glutamine concentrations compared to their singleton counterpart. Twins from LA-ewes had $32 \%$ lower $(P=0.02)$ tyrosine concentration compared to their singleton counterparts. No differences were observed for tyrosine in the other groups.

A two way interaction between pregnancy rank and maternal size was observed for arginine, glutamic acid, glycine and proline in ST muscle (Table 2). Twins from H-ewes had 40\% lower $(P<0.0001)$ arginine concentration than their singleton counterparts, whereas twins

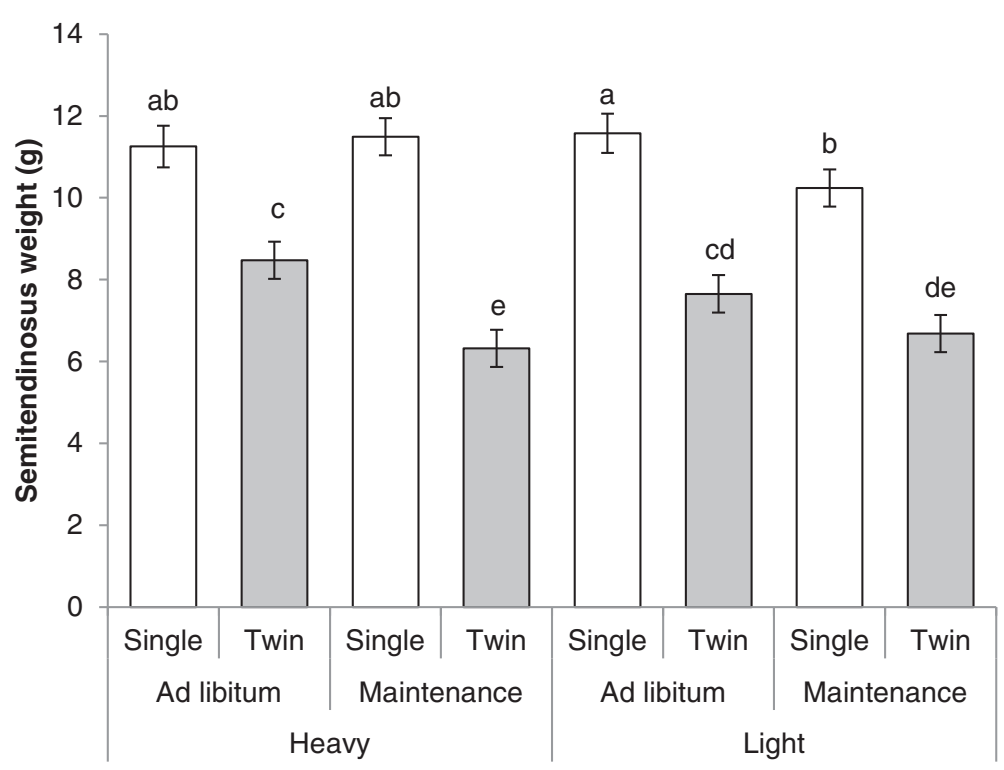

Figure 1 Fetal semitendinosus muscle weight. The bars graphic represent the semitendinosus muscle weight ( $\mathrm{g}$ ) of the eight groups of fetuses (singletons and twins from heavy and light ewes offered an ad libitum or maintenance feeding regime) at 140 days gestation, not adjusted by fetal weight. Bars with different letters are significantly different at $P \leq 0.05$. 
Table 1 Free amino acid concentration in semitendinosus muscle: three-way interaction

\begin{tabular}{|c|c|c|c|c|c|c|c|c|c|c|}
\hline & \multicolumn{4}{|c|}{ Heavy ewes } & \multicolumn{4}{|c|}{ Light ewes } & \multirow[t]{3}{*}{ LSD } & \multirow{3}{*}{$\begin{array}{c}P \\
\mathrm{RxSxN}\end{array}$} \\
\hline & \multicolumn{2}{|c|}{ Ad libitum } & \multicolumn{2}{|c|}{ Maintenance } & \multicolumn{2}{|c|}{ Ad libitum } & \multicolumn{2}{|c|}{ Maintenance } & & \\
\hline & Single & Twin & Single & Twin & Single & Twin & Single & Twin & & \\
\hline \multicolumn{11}{|c|}{ Essential amino acids } \\
\hline L-Histidine & 225 & 242 & 201 & 232 & 199 & 261 & 227 & 259 & 76 & 0.57 \\
\hline L-Leucine & 60 & 52 & 54 & 40 & 50 & 42 & 60 & 47 & 15 & 0.96 \\
\hline L-Lysine & 109 & 115 & 80 & 81 & 67 & 88 & 70 & 119 & 37 & 0.37 \\
\hline L-Methionine & 48 & 79 & 42 & 64 & 46 & 86 & 46 & 74 & 17 & 0.85 \\
\hline L-Phenylalanine & 41 & 50 & 47 & 37 & 44 & 43 & 48 & 47 & 13 & 0.18 \\
\hline L-Threonine & 1252 & 823 & 968 & 841 & 1222 & 839 & 1212 & 1065 & 287 & 0.82 \\
\hline L-Valine & 175 & 98 & 119 & 69 & 150 & 121 & 191 & 119 & 38 & 0.07 \\
\hline Total EAA & 1,690 & 1,423 & 1,455 & 1,272 & 1,763 & 1,462 & 1,707 & 1,713 & 185 & 0.55 \\
\hline \multicolumn{11}{|c|}{ Non essential amino acids } \\
\hline L-Alanine & 2393 & 2495 & 2239 & 1858 & 2137 & 2164 & 2400 & 2164 & 368 & 0.55 \\
\hline L-Arginine $^{1}$ & 410 & 239 & 424 & 263 & 392 & 263 & 340 & 333 & 88 & 0.20 \\
\hline L-Aspartic Acid & 465 & 302 & 132 & 85 & 500 & 343 & 423 & 345 & 96 & 0.70 \\
\hline L-Carnosine & 1407 & 1379 & 1297 & 1124 & 1157 & 1432 & 1148 & 1088 & 323 & 0.56 \\
\hline L-Citrulline & 75 & 53 & 59 & 52 & 87 & 72 & 92 & 97 & 27 & 0.86 \\
\hline L-Cystathionine & 140 & 97 & 218 & 157 & 153 & 169 & 287 & 208 & 102 & 0.45 \\
\hline L-Glutamic acid & 1483 & 1240 & 1191 & 1201 & 1045 & 1807 & 1365 & 1835 & 369 & 0.14 \\
\hline L-Glutamine & $3202^{a}$ & $3276^{a}$ & $3111^{a}$ & $1973^{b}$ & $3302^{a}$ & $3539^{a}$ & $3043^{a}$ & $3514^{a}$ & 609 & 0.02 \\
\hline L-Glycine & 1844 & 2794 & 2010 & 2868 & 1888 & 2215 & 2134 & 2052 & 543 & 0.56 \\
\hline L-Ornithine & 102 & 99 & 93 & 119 & 69 & 92 & 90 & 113 & 29 & 0.32 \\
\hline L-Proline & 352 & 246 & 370 & 295 & 319 & 285 & 322 & 391 & 105 & 0.51 \\
\hline L-Serine & 1353 & 1520 & 995 & 1474 & 772 & 1365 & 1239 & 1452 & 382 & 0.07 \\
\hline L-Taurine & 5501 & 6046 & 5786 & 5770 & 6170 & 6728 & 6485 & 6939 & 1348 & 0.74 \\
\hline L-Tyrosine & $51^{\mathrm{a}}$ & $57^{a}$ & $60^{a}$ & $52^{b}$ & $64^{a}$ & $44^{a}$ & $68^{a}$ & $72^{\mathrm{a}}$ & 17 & 0.03 \\
\hline Total NEAA & 18,634 & 19,640 & 17,665 & 17,238 & 17,766 & 19,831 & 19,361 & 20,227 & 895 & 0.90 \\
\hline TOTAL & 20,359 & 21,118 & 19,177 & 18,590 & 19,567 & 21,358 & 21,114 & 22,000 & 942 & 0.82 \\
\hline
\end{tabular}

${ }^{1}$ Deemed as conditionally essential (Wu 2009).

Three-way interaction between maternal size,(S, Heavy vs. Light) plane of nutrition ( $N$, Ad libitum vs. Maintenance) and pregnancy rank ( $R$, Single vs. Twin) for the concentration (nmol/g wet tissue) of free amino acids in M. semitendinosus of fetuses at 140 days gestation. Values are expressed as least square mean (LSM). The average of the difference of the least square means ( $L S D, a=0.05)$ and probability of significance for the three way interaction $(\mathrm{RxS} \times \mathrm{N})$ are presented.

from L-ewes had only $19 \%$ lower $(P=0.03)$ arginine concentration relative to singletons. Twins from L-ewes had $51 \%$ higher $(P<0.0001)$ concentration of glutamate compared to singletons, while no difference between pregnancy ranks was observed for fetuses from $\mathrm{H}$-ewes. Twin fetuses had $47 \%$ higher $(P<0.0001)$ glycine concentrations compared to singletons in the $\mathrm{H}$-ewes, while no differences were observed between twins and singletons from L-ewes. Twins had $25 \%$ lower $(P=0.02)$ proline concentration in $\mathrm{H}$-ewes while no difference between pregnancy ranks was observed for fetuses from L-ewes.

A pregnancy rank by nutrition interaction was observed for alanine and aspartic acid concentration in ST muscle (Table 2). Twin fetuses had 13\% lower $(P=0.02)$ alanine concentration compared to singletons in the M-ewes, while no difference was observed between pregnancy ranks in the A-ewes. For aspartic acid, twin fetuses from A-ewes had 33\% lower $(P<0.0001)$ concentration compared to singletons from A-ewes, while no difference was observed between ranks in the M-ewes group.

Compared to singletons, twins had lower ST muscle concentration of leucine (19\%), threonine (23\%), valine (36\%) and total EAA (11\%) (Table 2), but higher concentrations of methionine (67\%), ornithine (19\%), lysine $(23 \%)$, serine (33\%) and total non EAA (5\%) (Table 2).

A positive association was observed between ST muscle weight and arginine concentration after partial correlation analysis (Figure 2). In contrast, a negative 
Table 2 Free amino acid concentration in semitendinosus muscle: main effects and two way interactions

\begin{tabular}{|c|c|c|c|c|c|c|c|c|c|c|c|c|c|c|c|c|}
\hline & \multicolumn{4}{|c|}{ Rank } & \multicolumn{6}{|c|}{ Rank x Size } & \multicolumn{6}{|c|}{ Rank x Nutrition } \\
\hline & Single & Twin & LSD & $P$ & $\mathrm{H}-\mathrm{S}$ & $\mathrm{H}-\mathrm{T}$ & L-S & L-T & LSD & $P$ & A-S & A-T & M-S & $M-T$ & LSD & $P$ \\
\hline \multicolumn{17}{|c|}{ Essential amino acids } \\
\hline L-Histidine & 213 & 249 & 38 & 0.07 & 213 & 237 & 213 & 260 & 54 & 0.56 & 212 & 251 & 214 & 246 & 54 & 0.84 \\
\hline L-Leucine & 56 & 45 & 8 & 0.01 & 57 & 46 & 55 & 44 & 11 & 0.95 & 55 & 47 & 57 & 43 & 11 & 0.48 \\
\hline L-Lysine & 82 & 101 & 18 & 0.04 & 95 & 98 & 69 & 104 & 26 & 0.09 & 88 & 102 & 75 & 100 & 26 & 0.52 \\
\hline L-Methionine & 45 & 76 & 8 & $<0.001$ & 45 & 72 & 46 & 80 & 12 & 0.39 & 47 & 83 & 44 & 69 & 12 & 0.24 \\
\hline L-Phenylalanine & 45 & 44 & 7 & 0.85 & 44 & 44 & 46 & 45 & 9 & 0.94 & 43 & 47 & 47 & 42 & 9 & 0.18 \\
\hline L-Threonine & 1163 & 892 & 143 & $<0.001$ & 1110 & 832 & 1217 & 952 & 203 & 0.93 & 1237 & 831 & 1090 & 953 & 203 & 0.07 \\
\hline L-Valine & 159 & 102 & 19 & $<0.001$ & 147 & 83 & 171 & 120 & 27 & 0.49 & 163 & 109 & 155 & 94 & 27 & 0.71 \\
\hline Total EAA & 1,654 & 1,467 & 93 & 0.05 & 1,572 & 1,347 & 1,735 & 1,588 & 131 & 0.68 & 1,726 & 1,442 & 1,581 & 1,492 & 131 & 0.30 \\
\hline \multicolumn{17}{|c|}{ Non essential amino acids } \\
\hline L-Alanine & 2292 & 2170 & 184 & 0.19 & 2316 & 2176 & 2268 & 2164 & 260 & 0.85 & $2265^{\mathrm{ab}}$ & $2329^{a}$ & $2319^{a}$ & $2011^{b}$ & 260 & 0.05 \\
\hline L-Arginine $^{2}$ & 392 & 274 & 44 & $<0.001$ & $417^{\mathrm{a}}$ & $251^{\mathrm{b}}$ & $366^{\mathrm{a}}$ & $298^{\mathrm{a}}$ & 62 & 0.03 & 401 & 251 & 382 & 298 & 62 & 0.14 \\
\hline L-Aspartic Acid & 380 & 269 & 48 & $<0.001$ & 299 & 194 & 461 & 344 & 68 & 0.80 & $482^{a}$ & $323^{b}$ & $278^{b c}$ & $215^{c}$ & 68 & 0.05 \\
\hline L-Carnosine & 1252 & 1256 & 162 & 0.97 & 1352 & 1251 & 1152 & 1260 & 229 & 0.20 & 1282 & 1406 & 1222 & 1106 & 229 & 0.14 \\
\hline L-Citrulline & 78 & 69 & 14 & 0.16 & 67 & 53 & 90 & 84 & 19 & 0.52 & 81 & 63 & 76 & 74 & 19 & 0.22 \\
\hline L-Cystathionine & 200 & 158 & 51 & 0.11 & 179 & 127 & 220 & 189 & 72 & 0.69 & 147 & 133 & 253 & 183 & 72 & 0.27 \\
\hline L-Glutamic acid & 1271 & 1521 & 184 & 0.01 & $1337^{\mathrm{a}}$ & $1220^{a}$ & $1205^{\mathrm{a}}$ & $1821^{\mathrm{b}}$ & 261 & $<0.001$ & 1264 & 1523 & 1278 & 1518 & 261 & 0.92 \\
\hline L-Glutamine ${ }^{1}$ & 3165 & 3075 & 305 & 0.56 & 3156 & 2624 & 3173 & 3527 & 431 & $<0.001$ & 3252 & 3408 & 3077 & 2743 & 431 & 0.11 \\
\hline L-Glycine & 1969 & 2482 & 272 & $<0.001$ & 1927 & 2831 & 2011 & 2133 & 384 & 0.01 & 1866 & 2504 & 2072 & 2460 & 384 & 0.36 \\
\hline L-Ornithine & 89 & 106 & 14 & 0.02 & 98 & 109 & 80 & 102 & 20 & 0.42 & 86 & 95 & 91 & 116 & 20 & 0.30 \\
\hline L-Proline & 341 & 304 & 53 & 0.17 & $361^{a}$ & $270^{b}$ & $321^{\mathrm{ab}}$ & $338^{\mathrm{ab}}$ & 74 & 0.05 & 335 & 265 & 346 & 343 & 74 & 0.21 \\
\hline L-Serine & 1090 & 1453 & 191 & $<0.001$ & 1174 & 1497 & 1006 & 1408 & 270 & 0.68 & 1063 & 1442 & 1117 & 1463 & 270 & 0.86 \\
\hline L-Taurine & 5985 & 6371 & 674 & 0.26 & 5644 & 5908 & 6327 & 6834 & 953 & 0.72 & 5836 & 6387 & 6135 & 6354 & 953 & 0.62 \\
\hline L-Tyrosine $^{1}$ & 61 & 56 & 8 & 0.27 & 55 & 55 & 66 & 58 & 12 & 0.33 & 58 & 50 & 64 & 62 & 12 & 0.54 \\
\hline Total NEAA & 18,357 & 19,234 & 448 & 0.05 & 18,150 & 18,439 & 18,564 & 20,029 & 633 & 0.19 & 18,200 & 19,735 & 18,513 & 18,733 & 633 & 0.15 \\
\hline TOTAL & 20,054 & 20,767 & 471 & 0.14 & 19,768 & 19,854 & 20,341 & 21,679 & 666 & 0.19 & 19,963 & 21,238 & 20,146 & 20,295 & 666 & 0.24 \\
\hline
\end{tabular}

${ }^{1}$ Refer to Table 1 due to the existence of a three way interaction.

${ }^{2}$ Deemed as conditionally essential (Wu 2009).

Rank effect (Single (S) vs. Twin (T)), two way interaction between pregnancy rank and maternal size (Heavy (H) vs. Light (L)) and between pregnancy rank and plane of nutrition (Ad libitum (A) vs. Maintenance (M)) for the concentration (nmol/g wet tissue) of FAA in M. semitendinosus of fetuses at 140 days gestation. Values are expressed as least square mean (LSM). The average of the difference of the least square means (LSD, $a=0.05)$ is presented.

correlation was found between ST muscle weight and intracellular concentration of taurine (Figure 3). No correlations were found for any other FAA with ST muscle weight (data not shown).

\section{Discussion}

The objective of this study was to explore the potential relationship between skeletal muscle weight and intracellular FAA concentration in single compared to twin fetuses in late gestation sheep. An additional objective of this study was to establish the effect of maternal size and nutrition on fetal muscle FAA concentration, as an approach to understand some of the possible mechanisms explaining the lower muscle mass normally observed in twin fetuses (McCoard et al. 2001). Reduced ST mass in twins compared to singleton fetuses at 140 days gestation was associated with changes in the concentration of specific but not total intracellular FAA concentration. Notably, the concentrations of arginine, leucine, valine, and glutamine, known to influence pathways which regulate protein synthesis (Wu 2009), were lower in muscle of twin compared to single fetuses. While other AA were affected by pregnancy rank, maternal size or nutrition, their role in fetal muscle growth, beyond being the building blocks for protein synthesis, is unclear. Arginine concentration, irrespectively of pregnancy rank, maternal size and maternal nutrition, was the only AA positively correlated with fetal skeletal muscle mass. These results suggest that arginine may be important for skeletal muscle growth in the late-gestation ovine fetus.

Irrespective of maternal size or maternal nutrition, twin fetuses had lower ST muscle mass compared to 


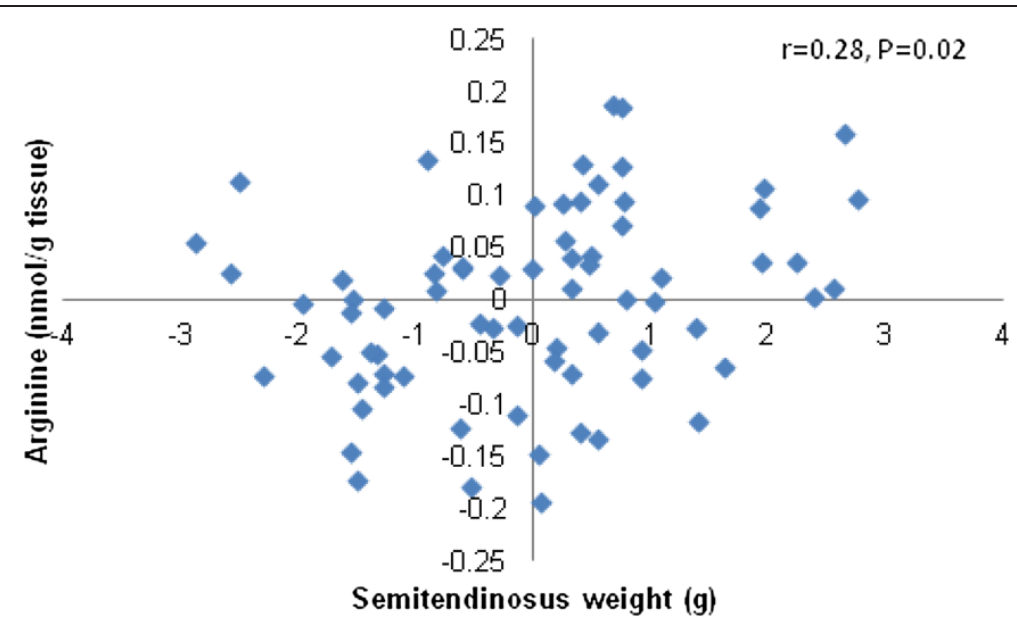

Figure 2 Partial correlation plot for ST muscle weight with arginine concentration. The plot graphic shows the partial correlation analysis for ST muscle weight $(\mathrm{g}$ ) with arginine concentration (nmol/g wet tissue). The analysis considered pooled data of all fetuses and was performed after accounting for the effects of pregnancy rank, maternal size and nutrition.

singletons, in agreement with a previous study (McCoard et al. 2001). In the present study, the effect of maternal nutrition on muscle mass was influenced by maternal size. Twin fetuses from HM-ewes had disproportionately smaller ST muscle compared to their single counterparts. This indicates that heavy twin-bearing ewes fed a maintenance plane of nutrition were unable to meet the nutritional requirements to maintain not only fetal weight (Blair et al. 2011), but also muscle growth, when compared to their counterparts carrying singletons. Competition for limited nutrients between twins (McCoard et al. 2000) or the reduced priority of nutrient partitioning to fetal skeletal muscle development compared with other organs during maternal nutrient restriction ( $\mathrm{Du}$ et al. 2010) could explain the lower muscle mass in twins from ewes at a restricted feeding level. In contrast, the lower ST muscle weight observed in singles and twins from LM-ewes, in comparison with their single and twin counterpart from LA-ewes, could indicate that lighter ewes fed a maintenance level of nutrition are unable to provide the nutrient requirements either for a single or twin pregnancy. These results support the notion that skeletal muscle growth in twins is more sensitive to maternal nutritional constraint than in singles, which is in agreement with a previous study (Gootwine et al. 2007). However, our results also suggest muscle growth can be compromised in singleton pregnancies under maternal nutrient restriction, as reported previously (Quigley et al. 2008).

Free AA plays a major role not only as building blocks for protein synthesis, but they also regulate key metabolic

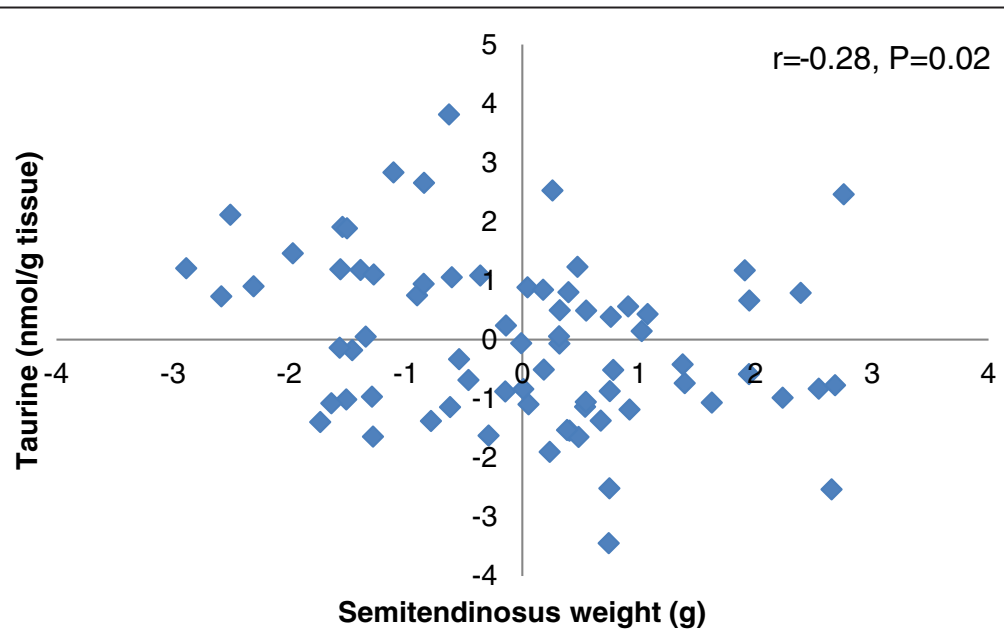

Figure 3 Partial correlation plot for ST muscle weight with taurine concentration. The plot graphic shows the partial correlation analysis for ST muscle weight (g) with taurine concentration (nmol/g wet tissue). The analysis considered pooled data of all fetuses and was performed after accounting for the effects of pregnancy rank, maternal size and nutrition. 
pathways which are necessary for cell maintenance and growth (Wu 2009). The function of FAA as signalling molecules is associated with changes in the intracellular concentration of specific FAA (Beugnet et al. 2003; Christie et al. 2002; Sancak et al. 2008). Intracellular pools are therefore critical to accomplish the signalling function of FAA (Nobukuni et al. 2005). The size and composition of the intracellular FAA pool depends on different processes, including availability of circulating FAA, and an increased AA influx or efflux between muscle and the plasma resulting from utilization, (e.g., by protein synthesis) or catabolism (protein turnover) (Hundal and Taylor 2009; Proud 2004). In this study it is unclear what the contribution is of each of these processes to the observed differences in intracellular FAA profiles. Unfortunately, fetal plasma was not available in the present study to relate the plasma FAA profile with intracellular muscle FAA profile in single and twin fetuses. However, we have previously shown that twins from ad libitum-fed ewes have lower plasma concentration of glutamine, arginine and leucine compared with singletons at day 140 of pregnancy (van der Linden et al. 2012). Others have also reported a decreased concentration of arginine family members and branched-chain amino acids (BCAA) in fetal plasma when restricting maternal nutrition to $50 \%$ of their requirement (Kwon et al. 2004). It has also been proposed that reduced muscle mass in sheep fetuses exposed to maternal nutrient restriction may be associated with reduced plasma FAA, particularly serine, arginine-family AA, and BCAA (Zhu et al. 2006). Therefore, it is feasible that changes in specific FAA concentration in twins muscle were related to changes in circulating AA availability. The possible association between pregnancy rank and maternal nutrition on fetal plasma AA concentration and how this affects intracellular muscle FAA concentrations and muscle mass, is yet to be established.

Skeletal muscle growth in fetuses utilizes both EAA and non-essential AA (NEAA) (Wilkening et al. 1994). However, during fetal stress, such as maternal fasting, AA catabolism increases in muscle, resulting in release to the circulation of gluconeogenic precursors such as glutamine (Liechty and Lemons 1984), due to an increased metabolism of BCAA (Liechty et al. 1987). In the present study, the reduced concentration of the BCAA leucine and valine in ST muscle of twins compared to singletons could suggest higher muscle protein breakdown in twins, resulting in a lower muscle mass compared to singles. In addition, protein breakdown may have also contributed to the observed reduction in glutamine concentration in ST muscle of twin fetuses from HM-ewes. This may have led to the higher growth limitation of muscle from fetuses in the HM group, reinforcing the idea of a greater degree of restriction in this group. Whether the difference in intracellular concentration of FAA is related to changes in FAA transport or a result of catabolism, warrants further investigation.

Arginine is considered a conditionally indispensable AA for the fetus (Wu et al. 2009) and participates in the synthesis of proteins, nitric oxide, polyamines, creatine, some AA and agmatine (Wu and Morris 1998), playing a major role in skeletal muscle growth (Wu et al. 2000). The exacerbated reduction in arginine concentration observed in twins compared to singles from $\mathrm{H}$-ewes compared to their L-ewes counterparts, may be associated with a more stressful fetal environment. Reduced concentration of arginine family members as a result of maternal undernutrition, has been previously described in fetal plasma (Kwon et al. 2004) and in gastrocnemius muscle of sheep fetuses (Wu et al. 2006), which supports our findings. The reduced concentration of arginine, could be due to a higher catabolism of this AA, which would explain the increase in ornithine concentration observed in twins compared with singletons, according to $\mathrm{Wu}$ and Morris (1998). The higher concentration of arginine found in singletons compared to twins and the positive, although weak partial correlation between intracellular muscle arginine with muscle mass, suggests that arginine may act as a limiting AA for fetal muscle growth in twin fetuses.

Protein synthesis in muscle is controlled by specific signalling pathways, including phosphatidylinositol-3 kinase (Schiaffino and Mammucari 2011), 5' -AMP-activated protein kinase (Bolster et al. 2002) and mitogen-activated protein kinase (Williamson et al. 2003). However, mTOR is accepted as the major pathway regulating muscle protein synthesis (Du et al. 2005). Intracellular FAA can activate mTOR (Beugnet et al. 2003), whereas a decrease in the intracellular AA concentration reduces the mTOR signalling (Sancak et al. 2008). Specific AA such as leucine (Escobar et al. 2006; Suryawan et al. 2008; Suryawan et al. 2011) and arginine (Yao et al. 2008) activate mTOR in muscle of monogastrics, as well as glutamine in cell culture models (Chiu et al. 2012; Nicklin et al. 2009). Preliminary evidence indicates a reduced abundance of mTOR downstream targets in muscle of twin fetuses, compared with singletons at late gestation (Sciascia et al. 2010). Therefore, it is possible that reduced intracellular concentrations of glutamine, leucine and arginine in muscle of twins compared to singles in this study, could have resulted in a decreased mTOR signalling, and therefore, reduced muscle mass. This potential mechanism is part of future research.

The increase in methionine concentration in ST muscle from twins compared to singles is a novel finding. Methionine is an EAA, used to initiate protein synthesis (Kozak 1983); it is involved in DNA methylation (Waterland 2006), participates in oxidative processes (Hoshi and Heinemann 2001) and has other metabolic 
functions (Brosnan and Brosnan 2006). Previous studies in rats under starvation have shown the increased concentration of methionine in muscle as a result from high protein breakdown (Millward et al. 1974; Millward 1970). However, reduced utilisation from lower protein accretion cannot be excluded.

\section{Conclusions}

Reduced concentrations of specific FAA, which are known to play a role in muscle growth, could act as limiting factors for muscle hypertrophy in twin fetuses in late gestation. The effect of decreased concentration of leucine, valine, glutamine, and especially arginine on fetal skeletal muscle growth in late gestation requires further investigation. The consequences of a maintenance maternal nutrition and maternal weight on fetal muscle mass and concentration of some FAA, reinforces their importance for fetal muscle growth. Altogether, these findings establish a baseline for new studies to further define the role of AA in fetal muscle growth in sheep, and open new possibilities for future strategic nutritional interventions to improve skeletal muscle development.

\section{Materials and methods \\ Animals}

All procedures described in the present study were approved by the Animal Ethics Committee of Massey University, Palmerston North, New Zealand.

This study was part of a larger study where animal selection protocols, feeding regimens (Blair et al. 2011; Kenyon et al. 2009; Kenyon et al. 2011) and euthanasia procedures (Blair et al. 2011) were previously described. Briefly, the study design utilised two different maternal sizes, according to their weight and corresponding to the heaviest $(\mathrm{H} ; 60.8 \pm 0.18 \mathrm{~kg}$, condition score $3.02 \pm 0.03$ (1-5 scale (Jefferies 1961)) and lightest ( $\mathrm{L} ; 42.5 \pm 0.17 \mathrm{~kg}$, condition score $1.97 \pm 0.03$ ) Romney ewes, selected from a commercial flock. The ewes were randomly allocated to either a maintenance (M) or ad libitum (A) nutritional plane on pasture from day 21 after insemination until 140 days of gestation. Maintenance nutrition was designed to ensure that total ewe live weight increased in pregnancy at a level similar to that of the expected conceptus mass (Rattray 1986; Rattray et al. 1974). The maternal weight change in the maintenance group was coincident with the conceptus mass, which suggest ewes were close to maintenance (Blair et al. 2011; Kenyon et al. 2011). The ad libitum plane was designed to provide unrestricted herbage intake under grazing conditions. To achieve these nutritional regimens, ewes were grazed using a rotational system, as described by (Kenyon et al. 2009). Ewes were pregnancy scanned via ultrasound and their pregnancy rank determined (single and twin).
At 140 days of gestation, animals were euthanized and the ST muscle was excised from each fetus, weighed, and snap frozen in liquid nitrogen and stored at $-80^{\circ} \mathrm{C}$. The numbers of fetuses in each group, according to maternal size, maternal nutrition and pregnancy rank were: $\mathrm{HM}$ /single: 10; HM/twin: 10; HA/single: 9; HA/twin: 10; LM/single: 10; LM/twin: 10; LA/single: 10 and LA/twin: 10. The effect of ewe size, plane of nutrition and pregnancy rank on fetal weights have previously been reported by Firth et al. (2008), Kenyon et al. (2011) and Blair et al. (2011) as part of the same research program. To date, no comparison between single and twin muscle weight and AA concentration in muscle has been previously described for these animals.

\section{Intracellular free AA (FAA) profiles in fetal ST tissue}

Amino acids were determined by ion-exchange chromatography using post-column derivatization with ninhydrin. Approximately $150 \mathrm{mg}$ of ST tissue from each animal was homogenised in $1.75 \mathrm{~mL}$ of Seraprep (Pickering Laboratories, Alphatech Systems Ltd, Auckland, New Zealand) containing $20 \mu \mathrm{L}$ of L-2-Amino-3-guanidinopropionic acid hydrochloride $(25 \mu \mathrm{M} / \mathrm{mL})$ as an internal standard (Calbiochem-Behring Corp., La Jolla, CA, USA). Samples were left in ice for 20 minutes, and then $40 \mu \mathrm{L} 5.88 \mathrm{M}$ lithium hydroxide buffer (BDH Chemical, Poole, England) added, followed by centrifugation at $8000 \mathrm{~g}$ for 10 minutes. After centrifugation, samples were filtered using a $0.45 \mu \mathrm{m}$ cellulose acetate filter membrane (Advantec, Toyo Roshi, Tokyo, Japan). Supernatant was analysed for FAA using a Shimadzu LC10Ai high-performance liquid chromatography (HPLC) (Shimadzu Oceania Ltd., Auckland, New Zealand), fitted with a high-efficiency lithium-ion exchange column ( $3 \mathrm{~mm}$ ID $\times 150 \mathrm{~mm}$; Pickering Laboratories, Shimadzu Oceania Ltd., Auckland, New Zealand) and a Pickering PCX 3100 post-column reaction module (Pickering Laboratories, Shimadzu Oceania Ltd, Auckland, New Zealand). Injected volumes were $10 \mu \mathrm{L}$, at a flow rate of $0.3 \mathrm{~mL} / \mathrm{min}$ and a run time of 162 minutes between injections, using Li buffers as eluants and ninhydrin postcolumn derivatization (Csapó et al. 2008). Detection was performed at $570 \mathrm{~nm}$ for all FAA, except proline which was read at $440 \mathrm{~nm}$. Amino acids in samples were quantified on the basis of known amounts of standards (Shimadzu Oceania, Pickering Laboratories, USA) and their retention times, using LC Solution ver. 1.22 SP1 software (Shimadzu, Kyoto, Japan).

\section{Statistical analysis}

Fetal ST muscle weight and FAA concentration were analysed using the MIXED procedure (SAS 2006) with a linear model, which included the fixed effects of pregnancy rank (single vs. twin), ewe size ( $\mathrm{H}$ vs. $\mathrm{L}$ ) and ewe nutrition (A vs. M) and their two- and three-way 
interactions. Individual ewe tag was used as a random effect to adjust for twinning. Differences among least squares means were analysed using the PDIFF option of the MIXED procedure. To examine whether fetal ST weight was proportional to fetal weight, fetal weight was used as covariate in a separate analyses. Both adjusted and unadjusted values are presented for comparison. Sex of fetus had no effect on any traits of interest and was removed from the ST muscle and FAA models. Means are presented as least square means with least significant differences (LSD, 5\%). Isoleucine, asparagine and cystine were detected in only some animals, therefore these FAA were omitted from analysis. The results for the effect of maternal size, maternal nutrition and maternal nutrition by size interaction were not included and will be presented elsewhere.

To determine the correlation between ST muscle weight and intracellular FAA concentration, partial correlations (SAS 2006) were estimated on the residual of the AA concentration and muscle mass, after accounting for the effects of pregnancy rank, maternal size and nutritional treatments and results consider all animals. For all analysis, statistical significance was set at a probability value of $P \leq 0.05$.

\section{Abbreviations}

AA: Amino acids; EAA: Essential amino acid; FAA: Free amino acid; NEAA: Non essential amino acid; ST: Semitendinosus; BCAA: Branched-chain amino acids.

\section{Competing interests}

The authors declared that they have no competing interests.

\section{Authors' contributions}

The authors' contributions were as follows: FS, HB, PK, DP and SM designed the research; FS and SM conducted the research; HB and PK provided essential materials; FS, DP and SM analysed the data; FS, DP, HB, PK and SM wrote the paper; SM had the primary responsibility for the final content. All authors read and approved the final manuscript.

\section{Acknowledgements \\ The authors are grateful to Beef + Lamb NZ and Gravida: National Centre for Growth and Development, Massey University, Palmerston North and AgResearch Capability fund for providing funding assistance for this project. The first author was funded by the Programa Formación de Capital Humano Avanzado, Becas Chile, Comisión Nacional de Investigación Científica y Tecnológica (CONICYT) doctoral scholarship. Grateful acknowledgement also to the Gravida: National Centre for Growth and Development for providing a scientific writing retreat which contributed to the preparation of this manuscript, to Bryan Treloar for amino acid profiling, John Koolaard for his statistical support and Massey University technical and farm staff who participated in the development of the study.}

\footnotetext{
Author details

${ }^{1}$ Animal Nutrition Team, Animal Nutrition and Health Group, AgResearch, Grasslands Research Centre, Palmerston North, New Zealand. ${ }^{2}$ Gravida: National Research Centre for Growth and Development, Auckland, New Zealand. ${ }^{3}$ Institute of Veterinary, Animal and Biomedical Sciences, Massey University, Palmerston North, New Zealand. Instituto de Investigaciones Agropecuarias, Centro Regional Kampenaike, Punta Arenas, Chile.
}

Received: 27 June 2013 Accepted: 4 September 2013 Published: 23 September 2013

\section{References}

Barker DJ (1998) In utero programming of chronic disease. Clin Sci (Lond) 95(2):115-128

Beugnet A, Tee AR, Taylor PM, Proud CG (2003) Regulation of targets of mTOR (mammalian target of rapamycin) signalling by intracellular amino acid availability. Biochem J 372(Pt 2):555-566

Blair H, Der Linden DS, Jenkinson C, Morris S, Mackenzie D, Peterson S, Firth E, Kenyon P (2011) Do ewe size and nutrition during pregnancy affect foetus and foetal organ weight in twins? Livest Sci 142(1):99-107

Bolster DR, Crozier SJ, Kimball SR, Jefferson LS (2002) AMP-activated protein kinase suppresses protein synthesis in rat skeletal muscle through down-regulated mammalian target of rapamycin (mTOR) signaling. J Biol Chem 277(27):23977-23980

Brosnan JT, Brosnan ME (2006) The sulfur-containing amino acids: an overview. J Nutr 136(6):1636S-1640S

Brown LD, Rozance PJ, Barry JS, Friedman JE, Hay WW Jr (2009) Insulin is required for amino acid stimulation of dual pathways for translational control in skeletal muscle in the late-gestation ovine fetus. Am J Physiol Endocrinol Metab 296(1):E56-E63

Chiu M, Tardito S, Barilli A, Bianchi MG, Dall'Asta V, Bussolati O (2012) Glutamine stimulates mTORC1 independent of the cell content of essential amino acids. Amino acids 43:1-7

Christie GR, Hajduch E, Hundal HS, Proud CG, Taylor PM (2002) Intracellular sensing of amino acids in Xenopus laevis oocytes stimulates p70 S6 kinase in a target of rapamycin-dependent manner. J Biol Chem 277(12):9952-9957

Csapó J, Albert C, Lóki K, Csapó-Kiss Z (2008) Separation and determination of the amino acids by ion exchange column chromatography applying postcolumn derivatization. Acta Universitatis Sapientiae Alimentaria 1:5-29

De Boo HA, Van Zijl PL, Smith DC, Kulik W, Lafeber HN, Harding JE (2005) Arginine and mixed amino acids increase protein accretion in the growth-restricted and normal ovine fetus by different mechanisms. Pediatr Res 58(2):270-277

Du M, Tong J, Zhao J, Underwood KR, Zhu M, Ford SP, Nathanielsz PW (2010) Fetal programming of skeletal muscle development in ruminant animals. J Anim Sci 88(13 Suppl):E51-E60

Du M, Zhu MJ, Means WJ, Hess BW, Ford SP (2005) Nutrient restriction differentially modulates the mammalian target of rapamycin signaling and the ubiquitin-proteasome system in skeletal muscle of cows and their fetuses. J Anim Sci 83(1):117-123

Escobar J, Frank JW, Suryawan A, Nguyen HV, Kimball SR, Jefferson LS, Davis TA (2006) Regulation of cardiac and skeletal muscle protein synthesis by individual branched-chain amino acids in neonatal pigs. Am J Physiol Endocrinol Metab 290(4):E612-E621

Fahey A, Brameld J, Parr T, Buttery P (2005) The effect of maternal undernutrition before muscle differentiation on the muscle fiber development of the newborn lamb. J Anim Sci 83(11):2564-2571

Firth $\mathrm{EC}$, Rogers CW, Vickers M, Kenyon PR, Jenkinson CM, Blair HT, Johnson PL, Mackenzie DD, Peterson SW, Morris ST (2008) The bone-muscle ratio of fetal lambs is affected more by maternal nutrition during pregnancy than by maternal size. Am J Physiol Regul Integr Comp Physiol 294(6):R1890-R1894

Freetly HC, Leymaster KA (2004) Relationship between litter birth weight and litter size in six breeds of sheep. J Anim Sci 82(2):612-618

Gootwine E, Spencer TE, Bazer FW (2007) Litter-size-dependent intrauterine growth restriction in sheep. Animal 1:547-564

Gootwine E, Zenu A, Bor A, Yossafi S, Rosov A, Pollott G (2001) Genetic and economic analysis of introgression the B allele of the FecB (Booroola) gene into the Awassi and Assaf dairy breeds. Livest Prod Sci 71(1):49-58

Greenwood PL, Hunt AS, Hermanson JW, Bell AW (1998) Effects of birth weight and postnatal nutrition on neonatal sheep: I: body growth and composition, and some aspects of energetic efficiency. J Anim Sci 76(9):2354-2367

Hara K, Yonezawa K, Weng Q-P, Kozlowski MT, Belham C, Avruch J (1998) Amino acid sufficiency and mTOR Regulate p70 S6 Kinase and elF-4E BP1 through a common effector mechanism. J Biol Chem 273(23):14484-14494

Hoshi T, Heinemann SH (2001) Regulation of cell function by methionine oxidation and reduction. J Physiol 531(1):1-11

Hundal HS, Taylor PM (2009) Amino acid transceptors: gate keepers of nutrient exchange and regulators of nutrient signaling. Am J Physiol Endocrinol Metab 296(4):E603-E613

Jefferies B (1961) Body condition scoring and its use in management. Tasmanian J Agric 32:19-21 
Kenyon P, Blair H, Jenkinson C, Morris S, Mackenzie D, Peterson S, Firth E, Johnston $P$ (2009) The effect of ewe size and nutritional regimen beginning in early pregnancy on ewe and lamb performance to weaning. New Zeal J Agr Res 52(2):203-212

Kenyon P, van der Linden D, Jenkinson C, Morris S, Mackenzie D, Peterson S, Firth E, Blair H (2011) The effect of ewe size and nutritional regimen beginning in early pregnancy on development of singleton foetuses in late pregnancy. Livest Sci 142(1):92-98

Kozak M (1983) Comparison of initiation of protein synthesis in procaryotes, eucaryotes, and organelles. Microbiol Rev 47(1):1-45

Kwon H, Ford SP, Bazer FW, Spencer TE, Nathanielsz PW, Nijland MJ, Hess BW, Wu G (2004) Maternal nutrient restriction reduces concentrations of amino acids and polyamines in ovine maternal and fetal plasma and fetal fluids. Biol Reprod 71(3):901-908

Liechty EA, Boyle DW, Moorehead H, Auble L, Denne SC (1999) Aromatic amino acids are utilized and protein synthesis is stimulated during amino acid infusion in the ovine fetus. J Nutr 129(6):1161-1166

Liechty EA, Lemons JA (1984) Changes in ovine fetal hindlimb amino acid metabolism during maternal fasting. Am J Physiol-Endoc M 246(5):E430-E435

Liechty EA, Polak MJ, Lemons JA (1987) Branched-chain amino acid carbon and nitrogen arteriovenous concentration differences across the ovine fetal hindlimb. Pediatr Res 21(1):44-48

McCoard S, McNabb W, Peterson S, McCutcheon S, Harris P (2000) Muscle growth, cell number, type and morphometry in single and twin fetal lambs during mid to late gestation. Reprod Fertil Dev 12:319-327

McCoard SA, McNabb WC, Birtles MJ, Harris PM, McCutcheon SN, Peterson SW (2001) Immunohistochemical detection of myogenic cells in muscles of fetal and neonatal lambs. Cells Tissues Organs 169(1):21-33

Millward D, Nnanyelugo D, James W, Garlick P (1974) Protein metabolism in skeletal muscle: the effect of feeding and fasting on muscle RNA, free amino acids and plasma insulin concentrations. Brit J Nutr 32(01):127-142

Millward DJ (1970) Protein turnover in skeletal muscle: 2: the effect of starvation and a protein-free diet on the synthesis and catabolism of skeletal muscle proteins in comparison to liver. Clin Sci 39:591-603

Morel P, Morris S, Kenyon P (2009) Effects of birth weight on survival in twin born lambs. Proc NZ Soc Anim Prod 69:75-79

Nicklin P, Bergman P, Zhang B, Triantafellow E, Wang H, Nyfeler B, Yang H, Hild M, Kung C, Wilson C, Myer VE, MacKeigan JP, Porter JA, Wang YK, Cantley LC, Finan PM, Murphy LO (2009) Bidirectional transport of amino acids regulates mTOR and autophagy. Cell 136(3):521-534

Nobukuni T, Joaquin M, Roccio M, Dann S, Kim S, Gulati P, Byfield M, Backer J, Natt F, Bos J (2005) Amino acids mediate mTOR/raptor signaling through activation of class 3 phosphatidylinositol 3OH-kinase. Sci STKE 102(40):14238

Pacheco D, Treloar BP, Kenyon PR, Blair HT, McCoard S (2010) Brief Communication: Intracellular concentrations of free amino acids are reduced in skeletal muscle of late gestation twin compared to single fetuses. Proc NZ Soc Anim Prod 70:199-20

Proud CG (2004) mTOR-mediated regulation of translation factors by amino acids. Biochem Bioph Res Co 313(2):429-436

Quigley SP, Kleemann DO, Walker SK, Speck PA, Rudiger SR, Nattrass GS, DeBlasio MJ, Owens JA (2008) Effect of variable long-term maternal feed allowance on the development of the ovine placenta and fetus. Placenta 29(6):539-548

Rattray P (1986) Feed requirements for maintenance, gain and production. In: McCutcheon SN, McDonald MF, Wickham GA (eds) 'Sheep production': feeding, growth and health, Ilth edn. Ray Richards Publishers, Wellington, New Zealand, pp 75-109

Rattray PV, Garrett WN, East NE, Hinman N (1974) Growth, development and composition of the ovine conceptus and mammary gland during pregnancy. J Anim Sci 38(3):613-626

Sancak Y, Peterson TR, Shaul YD, Lindquist RA, Thoreen CC, Bar-Peled L, Sabatini DM (2008) The rag GTPases bind raptor and mediate amino acid signaling to mTORC1. Science 320(5882):1496-1501

SAS (2006) Statistical analysis system. SAS Institute Inc., Cary, NC, USA

Schiaffino S, Mammucari C (2011) Regulation of skeletal muscle growth by the IGF1-Akt/PKB pathway: insights from genetic models. Skeletal Muscle 1(1):1-14

Sciascia Q, Pacheco D, Bracegirdle J, Berry C, Kenyon P, Blair H, Senna Salerno M, Nicholas G, McCoard S (2010) Brief communication: effects of restricted fetal nutrition in utero on mTOR signalling in ovine skeletal muscle. Proc NZ Soc Anim Prod 70:180-182
Suryawan A, Jeyapalan AS, Orellana RA, Wilson FA, Nguyen HV, Davis TA (2008) Leucine stimulates protein synthesis in skeletal muscle of neonatal pigs by enhancing mTORC1 activation. Am J Physiol Endocrinol Metab 295(4):E868-E875

Suryawan A, Orellana RA, Fiorotto ML, Davis TA (2011) Triennial growth symposium: leucine acts as a nutrient signal to stimulate protein synthesis in neonatal pigs. J Anim Sci 89(7):2004-2016

Tan B, Yin Y, Liu Z, Li X, Xu H, Kong X, Huang R, Tang W, Shinzato I, Smith S, Wu G (2009) Dietary L-arginine supplementation increases muscle gain and reduces body fat mass in growing-finishing pigs. Amino Acids 37(1):169-175

van der Linden DS, Sciascia Q, Sales F, McCoard SA (2012) Placental nutrient transport is affected by pregnancy rank in sheep. J Anim Sci. doi:10.2527/ jas.2012-5629

Waterland RA (2006) Assessing the effects of high methionine intake on DNA methylation. J Nutr 136(6):1706S-1710S

Wilkening RB, Boyle DW, Teng C, Meschia G, Battaglia FC (1994) Amino acid uptake by the fetal ovine hindlimb under normal and euglycemic hyperinsulinemic states. Am J Physiol-Endoc M 266(1):E72-E78

Williamson D, Gallagher P, Harber M, Hollon C, Trappe S (2003) Mitogen-activated protein kinase (MAPK) pathway activation: effects of age and acute exercise on human skeletal muscle. J Physiol 547(3):977-987

Wu G (2009) Amino acids: metabolism, functions, and nutrition. Amino Acids 37(1):1-17

Wu G, Bazer F, Davis T, Kim S, Li P, Marc Rhoads J, Carey Satterfield M, Smith S, Spencer T, Yin Y (2009) Arginine metabolism and nutrition in growth, health and disease. Amino Acids 37(1):153-168

Wu G, Bazer FW, Wallace JM, Spencer TE (2006) Board-invited review: intrauterine growth retardation: implications for the animal sciences. J Anim Sci 84 (9):2316-2337

Wu G, Meininger CJ, Knabe DA, Baze FW, Rhoads JM (2000) Arginine nutrition in development, health and disease. Curr Opin Clin Nutr 3(1):59-66

Wu G, Morris SM Jr (1998) Arginine metabolism: nitric oxide and beyond. Biochem J 336(Pt 1):1-17

Yao K, Yin Y-L, Chu W, Liu Z, Deng D, Li T, Huang R, Zhang J, Tan B, Wang W, Wu $G$ (2008) Dietary arginine supplementation increases mtor signaling activity in skeletal muscle of neonatal pigs. J Nutr 138(5):867-872

Zhu MJ, Ford SP, Means WJ, Hess BW, Nathanielsz PW, Du M (2006) Maternal nutrient restriction affects properties of skeletal muscle in offspring. J Physiol 575(Pt 1):241-250

doi:10.1186/2193-1801-2-483

Cite this article as: Sales et al:: Muscle free amino acid profiles are related to differences in skeletal muscle growth between single and twin ovine fetuses near term. SpringerPlus 2013 2:483.

\section{Submit your manuscript to a SpringerOpen ${ }^{\odot}$ journal and benefit from:}

- Convenient online submission

- Rigorous peer review

- Immediate publication on acceptance

- Open access: articles freely available online

- High visibility within the field

- Retaining the copyright to your article

Submit your next manuscript at $>$ springeropen.com 